\title{
The possible role of GPI-ceruloplasmin in hypoxia de novo creation and maintenance
}

\author{
Roberto Arrigoni \\ Department of Biosciences, Biotechnologies and Biopharmaceutics, Laboratory of Biochemistry and Molecular Biology, University \\ of Bari; CNR Institute of Biomembranes and Bioenergetics, via Orabona 4, 70125 Bari, Italy
}

\section{Email address:}

r.arrigoni@ibbe.cnr.it

To cite this article:

Roberto Arrigoni. The Possible Role of GPI-Ceruloplasmin in Hypoxia De Novo Creation and Maintenance. Advances in Biochemistry. Vol. 1, No. 2, 2013, pp. 22-27. doi: 10.11648/j.ab.20130102.13

\begin{abstract}
Ceruloplasmin is a member of the multicopper oxidases family (MCOs), multidomain proteins capable of oxidizing many structurally unrelated compounds reducing oxygen to water. While MCOs show great oxidative versatility, they can only transfer electrons to molecular oxygen, which is the obligate electron acceptor. Therefore, MCOs should also be considered as " $\mathrm{O}_{2}$ consuming enzymes". The glycosylphosphatidylinositol anchored ceruloplasmin (GPI-Cp) isoform present on the surface of the plasma membrane, does not seem to be involved in copper and iron metabolism. Since hypoxia is also a common feature of many rapidly growing solid tumors, we postulate that the regulation of GPI-Cp could be the molecular event in the creation and the maintenance of hypoxia in tumor cells. By inhibiting the GPI-Cp expression, it would appear possible to attempt to overcome tumor hypoxia, thus improving the efficiency of radiotherapy.
\end{abstract}

Keywords: Hypoxia, Glycosylphosphatidylinositol-Ceruloplasmin, Multicopper Oxidases, Oxygen-Consuming Enzyme, Tumor

\section{Introduction}

Aerobic life survival depends on molecular oxygen, so when changes occur that result in an increase or a decrease of molecular oxygen, respectively hyperoxia and hypoxia, the body must cope with a crisis that leads to the depletion of energy reserves, changes in signal cascade, oxidative stress, cell death and tissue damage. Normoxia means a level of oxygen sufficient to take place within the normal physiological processes of cells, tissues and / or organs [1]. While have been established some guidelines, there are no values $\left(\mathrm{pO}_{2}\right)$ of partial pressure of oxygen $\left(\mathrm{pO}_{2}\right)$ to define the absolute "'hypoxia". Oxygen levels dictate a change in hypoxic direction depending on the system (cell / tissue / organ) [1]. In general, $\mathrm{pO}_{2}$ less than or equal to $5 \%$ is indicative of hypoxia in the cellular systems. $\mathrm{PO}_{2}$ levels of between 5 and $2 \%$ correspond to a condition of moderate hypoxia, while levels $<2 \%$ represent a condition of marked hypoxia.

The $\mathrm{O}_{2}$ supply is finely regulated in vivo, with respect to the cell and tissue type. The tissue $\mathrm{O}_{2}$ concentrations are much lower than the atmospheric ones. One of the responses at the molecular level consists in the activation of specific transcription factors, or inducible by hypoxia, called HIF (Hypoxia Inducible Factors) [2]. HIF complexes are hetero-dimeric compounds from an $\alpha$ subunit, whose stability is oxygen-dependent and oxygenindependent $\beta$ subunit. Have been identified three subunits $\alpha(1 \alpha, 2 \alpha$ and $3 \alpha)$ and a $\beta$ subunit (also called ARNT, Aryl-hydrocarbon Receptor Nuclear Translocator), each with several splice variants [2- 3]. In normoxic conditions, in the cytoplasm, the $\alpha$ subunits undergo two hydroxylation events catalyzed by PHDs (prolyl hydroxylase domain proteins) and FIH (factor inhibiting HIF) enzymes, that causes the proteasomemediated degradation [2]. Under hypoxic conditions, the PHDs and FIH enzymes are inactive due to the lack of oxygen necessary to the hydroxylation reactions. In this way, the $\alpha$ subunit is stabilized, and translocates to the nucleus to bind to the $\beta$ subunit, forming a heterodimer (HIF $\alpha$ / HIF $\beta$ ) which represents the active form of HIF, able to function as transcription factor.

Hypoxia is a critical component of the microenvironment of tumor cells: metabolic changes, drug resistance, protein overexpression, inhibition of apoptosis, induction of autophagy are all part of the cellular reprogramming triggered by HIFs [1, 4-5]. Interestingly, recent findings have also indicated that HIF- $1 \alpha$ and HIF- $2 \alpha$ play critical roles for the gain of more malignant phenotypes by highly tumourigenic 
cancer stem/progenitor cells that are able to generate the bulk mass of heterogeneous and differentiated cancer cells within tumours and which are involved in primary cancer progression, metastases, resistance to current cancer therapies and disease relapse [6]. Hypoxia is a pivotal driving force of malignant progression [7]: it is well known that can induce tumor metastasis [1]. Most of human solid tumors contain hypoxic areas [8]; increased levels of tumor hypoxia have been associated with worse clinical outcomes in patients of Glioblastoma multiforme, the most malignant brain tumor [9], by compromising the effectiveness of chemotherapy [3].

The causes of tumor hypoxia are multifactorial, but at the present it is widely accepted that poorly oxygenated areas within solid tumors are due to aberrant blood vessel formation [10]. However, there is a growing body of experimental evidence that strongly suggests that tumor hypoxia is a more complex phenomenon and that in part it is programmed by the tumoral cell itself. Recently, it has been demonstrated that in human pancreatic cancer the severe hypoxia that characterizes this tumor is found not just in the center of the tumor mass, but also occurs at the invasion front [11]. Furthermore, it has been shown that microscopic tumors, less than $1 \mathrm{~mm}$ in diameter, are severely hypoxic [12].

The state of hypoxia is generally associated with pathological conditions, such as cerebral ischemia, disorders of the inflammatory response, diabetes and solid tumors, in which it is observed an increased cell proliferation associated with hypoxia [2, 4]. However hypoxic conditions are also observed in normal physiological processes, such as during fetal development, proliferation and cell differentiation, in the reparative processes of the tissues and in hematopoietic tissue [13]. In some tissues there are some real gradients of $\mathrm{pO}_{2}$, such as in bone marrow, for which the cells closest to the vascular sinusoids are exposed to high $\mathrm{pO}_{2}$ around 5-7\%, while those present in the site furthest at the level of endosteum are exposed to much lower levels of $\mathrm{pO}_{2}$, up to $0.1 \%$ [13]. Endosteal regions are rich in hematopoietic stem cells (HSCs) and the physiological condition of hypoxia is essential for the maintenance of stem cell of these cells. Fluctuations in the local concentration of oxygen induce the system - cell or body - to implement adaptation strategies that determine protection or limitation of damages. In the presence of low concentrations of oxygen, the cell reacts with a series of coordinated responses times to restore the ideal levels of $\mathrm{O}_{2}[2,3]$.

Beside pathophysiology, hypoxia also has a role in the function of normal tissues. In bone marrow, the hematopoietic stem cell (HSC) reside in well-defined microenvironmental domains called "niches" where they are maintained in a "quiescent state" by low oxygen concentration, ie, in the condition of hypoxia. The bone marrow appears to be the only one among the normal tissues to be physiologically in conditions of hypoxia [14]. Within the bone, anoxic regions exist (ie entirely without $\mathrm{O}_{2}$ ) to protect HSCs from damage caused by oxygen free radicals. HSCs in the bone would also be organized in a manner dependent on the oxygen gradient: from a greater amount of HSCs within the bone, in areas with a lower oxygenation (hypoxia), it goes to drastically lower amount of CSE in most areas "superficial "as it increases oxygenation [14].

The adaptation induced by increased oxygenation of atmosphere conditioned the evolution of a complex circulatory and respiratory system to ensure an adequate $\mathrm{O}_{2}$ supply for every cell type in organism. The complex mechanisms such as cellular respiration require $\mathrm{O}_{2}$ as ultimate electron acceptor. But the need for $\mathrm{O}_{2}$ as a metabolic substrate is opposed to the risk of cellular macromolecules oxidative damage (ROS generation). That is why its concentration within cells is maintained within a narrow range that optimally balances supply and demand. A cell could and has to fight against the ROS in excess. Therefore, it is really important for the cell, tissue or whole organism, to be able to finely adjust and calibrate the entry of oxygen, in order to maintain the optimal concentration.

\section{Ceruloplasmin and GPI- Ceruloplasmin}

Ceruloplasmin is a protein secreted in the serum; it is a copper-containing globulin that has a molecular weight of 151,000 Dalton. The protein contains 6 tightly bound copper ions, in 3 different types of binding site. The active site of each MCO contains four copper atoms per functional unit: one type 1 or "blue" copper site and three other atoms in a trinuclear cluster. Type 1 copper, with redox potentials ranging from 400 to $790 \mathrm{mV}$ in the various MCOs, is the site where the oxidation of substrate molecules takes place [15]. The "blue" copper transfers electrons to the trinuclear cluster site which it then provides for the reduction of a molecule of oxygen into two molecules of water [16]. The redox potential for the type 3 is equal or to somewhat higher than the respective type 1 potential [15].

It is over 60 years since the discovery and isolation of the serum ceruloplasmin. In that time much basic information about the protein has been elucidated including its catalytic and kinetic properties as an enzyme, expression, sequence and structure. The importance of its biological role is indicated in genetic diseases such as aceruloplasminemia where its function is lost through mutation. Despite this wealth of data, fundamental questions about its action remain unanswered.

Despite the need for copper for the functions of ceruloplasmin, this protein plays no essential role in the transport or metabolism of the copper. The biological role of ceruloplasmin harboring a ferroxidase activity was demonstrated by Cartwright and colleagues in experiments using pigs with copper deficiency [17-19]. The copper depletion resulted in a marked decrease in the circulating serum ceruloplasmin in association with iron deficiency anemia that could only be corrected by 
administration of copper and iron accumulation in parenchymal tissues, while the administration of exogenous ceruloplasmin resulted in the prompt release of tissue iron with subsequent incorporation into circulating transferrin. The essential function of ceruloplasmin is as a ferroxidase, utilizing the electron chemistry of bound copper ions to couple the oxidation of ferrous iron $\left(\mathrm{Fe}^{2+}\right)$ to the reduction of oxygen bound to the trinuclear cluster [20,21].

In recent years, a ceruloplasmin isoform anchored by glycosylphosphatidylinositol (GPI-Cp) to the outer surface of the plasma membrane has been discovered in animal cells [22 - 23].

The GPI-Cp is generated by alternative RNA splicing of exons 19 and 20 [24]; originally found in astrocytes in the CNS, as well as in retina and hepatocytes. Recent studies revealed a much more ubiquitous expression of the GPI-Cp isoform, showing GPI-Cp detection in purified membranes of multiple organs of rats and mice [25]. Lately, it was demonstrated that both secreted $\mathrm{Cp}$ and membrane-bound $\mathrm{Cp}$ are coexpressed in several tissue, including immune cells as well as hepatocytes [26].

The expression of serum $\mathrm{Cp}$ and GPI-Cp in immune cells, namely lymphocytes and monocytes/macrophages, suggests a close functional relationship among immune system, oxidative stress and iron metabolism. In fact, Cp is an acute-phase protein with its plasma concentration increasing in many diseases including hepatitis, atherosclerosis, polyarthritis, cancer and many other inflammatory and infectious diseases [25].

The proposed physiological functions of ceruloplasmin include copper transport, oxidation of organic amines, ferroxidase activity, regulation of cellular iron levels, glutathione peroxidase and ascorbate oxidase activities and an antioxidant activity. Furthermore, it has also been

\section{Cp catalysed reaction \\ Non-catalysed reactions \\ (Fenton reaction) \\ (Haber-Weiss reaction)}

$$
\mathrm{Fe}(\mathrm{II})+{ }^{\bullet} \mathrm{O}_{2}{ }^{-}+2 \mathrm{H}^{+} \rightarrow \mathrm{Fe}(\mathrm{III})+\mathrm{H}_{2} \mathrm{O}_{2}
$$

\section{Multicopper Oxidase Protein: An Oxygen-Consuming Enzyme}

Ceruloplasmin is a member of the Multicopper oxidases family (MCOs). MCOs utilize the distinctive redox ability of copper ions, present in their active site, to drive electrons from the various electron donor substrates to molecular oxygen in a controlled way, i.e. forming two molecules of $\mathrm{H}_{2} \mathrm{O}$ without release of reactive oxygen species (ROS) [32].

Being capable of oxidizing several structurally unrelated compounds, both inorganic [Fe(II), $\mathrm{Cu}(\mathrm{I})$, $\mathrm{Mn}(\mathrm{II})]$ and organic (ascorbic acid, organic amines) [33, 34], MCOs are involved in various metabolic pathways. reported that ceruloplasmin may scavenge reactive oxygen species such as singlet (1O2), superoxide (O2) and hydroxyl radicals $(\mathrm{OH})$. However, it has also been shown to have prooxidant activities, which involve a distinct active site from the antioxidant sites.

In the last few years, this protein appears to be involved in several disease: an insufficiency of ceruloplasmin synthesis or its decreased activity in the cells of the central nervous system is currently regarded as one of the mechanisms underlying the development of a number of neurodegenerative disorders, such as Alzheimer's and Parkinson's disease [27, 28].

There is abundant evidence that ceruloplasmin plays a key role in iron metabolism. The importance of ferroxidase activity of $\mathrm{Cp}$ has been well demonstrated [29]. Humans with a mutation of the ceruloplasmin gene (aceruloplasminemia), which leads to inactivation of ferroxidase activity, are characterized by iron accumulation in the brain [30]. Several neurodegenerative disorders, such as Parkinson's and Alzheimer's diseases, have been associated with misregulation of iron metabolism in the central nervous system [31].

However, as stated above, it should be taken into consideration that $\mathrm{Cp}$, while oxidizing $\mathrm{Fe}(\mathrm{II})$ to $\mathrm{Fe}(\mathrm{III})$, consumes molecular oxygen and that the subsequent drop in oxygen concentration (de novo created hypoxia) induces a decrease in the rate of non-enzymatic oxidation of $\mathrm{Fe}(\mathrm{II})$, because the affinity of the reaction for $\mathrm{O} 2$ is fairly low. Conversely, the drop in $\mathrm{O} 2$ concentration does not affect the ferroxidase activity of $\mathrm{Cp}$ because its affinity for $\mathrm{O} 2$ is very high. Decreasing the nonenzymatic oxidation of $\mathrm{Fe}(\mathrm{II})$ is a very useful event because this uncatalyzed oxidation is so potentially dangerous that it can trigger the formation of many ROS as described below:

$$
\begin{gathered}
4 \mathrm{Fe}(\mathrm{II})+\mathrm{O}_{2}+4 \mathrm{H} \rightarrow 4 \mathrm{Fe}(\mathrm{III})+2 \mathrm{H}_{2} \mathrm{O} \\
\mathrm{Fe}(\mathrm{II})+\mathrm{O}_{2} \rightarrow \mathrm{Fe}(\mathrm{III})+{ }^{\bullet} \mathrm{O}_{2}^{-} \\
\mathrm{H}^{+} \rightarrow \mathrm{Fe}(\mathrm{III})+\mathrm{H}_{2} \mathrm{O}_{2} \\
\mathrm{Fe}(\mathrm{II})+\mathrm{H}_{2} \mathrm{O}_{2} \rightarrow{ }^{\bullet} \mathrm{OH}+\mathrm{OH}^{-}+\mathrm{Fe}(\mathrm{III}) \\
\operatorname{O}_{2}^{-}+\mathrm{H}_{2} \mathrm{O}_{2} \rightarrow{ }^{\bullet} \mathrm{OH}+\mathrm{OH}^{-}+{ }^{1} \mathrm{O}_{2}
\end{gathered}
$$

Furthermore, these enzymes can change their function in response to changes in substrate, composition of the reaction medium and differential cell localization or expression [17]. Since this multiplicity of actions does not conform to the "one gene-one protein-one function" paradigm, MCOs are called moonlighting proteins [34].

The multiplicity of actions of MCOs makes it difficult to decide which functions are important under what conditions. While MCOs show great oxidative versatility, they can only transfer electrons to molecular oxygen, which is the obligate electron acceptor [35]. Therefore, MCOs could also be considered as " $\mathrm{O}_{2}$-consuming enzymes" and this constitutes an important aspect of the role that these enzymes can play in the oxygen 
management of aerobic organisms, in both physiological and pathological conditions.

Since molecular oxygen is not subject to active transport outside the vascular system, there is a general conviction that delivery of $\mathrm{O}_{2}$ to the cells is driven by the concentration gradient set up by $\mathrm{O}_{2}$ consumption occurring in the cells and their compartments [36]. Oxygen traffic and distribution outside the vascular system is a more complex process that could be regulated, in part, by the activity of multicopper oxidases.

Until now nearly all research on MCOs has been focused on the electron donor(s) side of the reaction. Ceruloplasmin is involved in many biological processes (copper transport, amino acid neurotransmitter metabolism, nitric oxide synthase modulation, antioxidant activity) [37]. However, after 70 years of research, the main known function of $\mathrm{Cp}$ remains its ability to oxidize the more toxic ferrous ions $\left(\mathrm{Fe}^{2+}\right)$ to the less toxic ferric form to $\left(\mathrm{Fe}^{3+}\right)$ [38]. Remarkably, it has been almost completely disregarded that $\mathrm{Cp}$, while catalyzing iron oxidation, also act simultaneously as oxygen-consuming enzyme.

\section{Ceruloplasmin and Oxygen Relationship}

There are several reports in literature that show a direct link between oxygen concentration and ceruloplasmin. The ceruloplasmin amount increase in hypoxic condition; HIF is known to promote the ceruloplasmin expression in HepG2 cells. The ceruloplasmin promoter indeed contain an hypoxia-responsive element (HRE) recognized by HIF $\alpha$ and HIF $\beta$, respectively, and is indeed activated by Hypoxia-inducible factor-1 [39, 40].

Prolonged hypoxia can induce the mRNA ceruloplasmin transcription in mouse, and ceruloplasmin mRNA expression is also induced in the liver of hypoxic mice in vivo [41].; furthermore, in macrophages, the ceruloplasmin activity (iron release) was absolutely dependent on the presence of hypoxic condition [42].

Patients with chronic obstructive pulmonary diseases that induce hypoxia have a $35-100 \%$ increase in serum $\mathrm{Cp}$ [43]. In addition, exposure of healthy adults to high altitude hypoxia significantly increases serum $\mathrm{Cp}$ [44].

Furthermore, copper concentration can enhance ceruloplasmin expression, and is also able to activate HIF 1: thus, there are several different experimental data that support a functional relationship between oxygen levels and ceruloplasmin expression [41].

Experimentally, the ceruloplasmin expression is induced by raising the concentration of $\mathrm{O} 2$ in vivo, while dietary iron status has little effect on the expression of the enzyme [38, 45]. Recently it has been demonstrated that hypoxic treatment in syncytiotrophoblasts culture enhance ceruloplasmin expression by approximately 25 fold [46]. It has been shown that lower GPI-Cp did not correlate with tissue iron retention; furthermore, this $\mathrm{Cp}$ isoform does not seems to have any role in the iron metabolism [25].

On the basis of these data, indicating that in vivo activity of ceruloplasmin is regulated in response to oxygen availability, GPI-Cp could be part of a dynamic mechanism operating whenever cells have to control oxygen availability.

\section{A New Target to Improve Tumor Radiotherapy}

Cancer is presently a major cause of mortality in developed country: worldwide, it accounts for 7.6 million deaths (around 13\% of all deaths) in 2008, according to the World Health Organization report. Radiotherapy is almost always used to treat various forms of cancer. Ionizing radiation works by damaging the DNA of exposed tissue leading to cellular death: shaped radiation beams are aimed from several angles of exposure to intersect at the tumor, providing a much larger absorbed dose there than in the surrounding, healthy tissue. The radiation acts only on the part of the body that is exposed to the radiation. Radiation used for cancer treatment is called ionizing radiation because it forms ions (electrically charged particles) in the cells of the tissues it passes through. It creates ions by removing electrons from atoms and molecules. Unfortunately, solid tumors with hypoxic areas are the most aggressive and resistant to radiotherapy and this limits the radio curability of many tumors [47]; although several oxygenation approaches have been utilized, none of them is capable of restoring normoxia in the hypoxic areas present in tumors [48].

New therapeutic strategies such as guanine-rich oligodeoxynucleotides (G-rich ODNs), chemical compounds and chemotherapeutic drugs that target HIF$1 \alpha$ and/or HIF-2 $\alpha$ proteins and repress the expression of their target genes in various cancer cells have been shown to counteract primary cancer progression and metastases at distant sites, and reverse treatment resistance under normoxic and hypoxic conditions $[49,50]$.

The understanding of how hypoxia drives tumour progression is attracting substantial investigation; however, a lot remains to be done to clarify the molecular mechanism involved.

It is conceivable to hypothesize that tumor cells maintain a low oxygen concentration through the expression of GPI-anchored ceruloplasmin on their plasma membrane. It is possible that the major role of this GPI isoform of $\mathrm{Cp}$ is to regulate the entrance of oxygen into the cell.

A new line of research to improve the efficiency of tumor radiotherapy could target the GPI-ceruloplasmin. By regulating the expression/activity of this $\mathrm{Cp}$ isoform, the level of $\mathrm{O} 2$ in cells could be modulated; using small interfering RNA to inhibit GPI-Ceruloplasmin expression, it looks possible to overcome the state of hypoxia in 
tumor areas, increase partial $\mathrm{O} 2$ pressure, thus improving the efficiency of radiotherapy.

\section{References}

[1] J. A. Bertout, S. A. Patel, and M. C. Simon, "The impact of $\mathrm{O}_{2}$ availability on human cancer," Nat. Rev. Cancer 2008, vol. 8, pp. 967-975.

[2] M. C Brahimi-Horn., and J. Pouyssègur, "HIF at a glance," J. Cell Sci. 2009, vol. 122, pp. 1055-57

[3] S. Rocha, "Gene regulation under low oxygen: holding your breath for transcription," Trends Biochem. Sci. 2007, vol. 32, pp. 389-97.

[4] G. L. Semenza, "Molecular mechanisms mediating metastasis of hypoxic breast cancer cells," Trends Mol. Med. 2012, vol. 18, pp. 534-543.

[5] X. Lu and Y. Kang, "Hypoxia and hypoxia-inducible factors: master regulators of metastasis," Clin. Cancer Res. 2011, vol. 16, pp. 5928-5935.

[6] M. Mimeault, R. Hauke, P. P. Mehta, and S. K. Batra, "Recent advances on cancer stem/progenitor cell research: therapeutic implications for overcoming resistance to the most aggressive cancers," J. Cell Mol. Med. 2007, vol. 11, pp. 981-1011.

[7] J. P. Cosse and C. Michiels, "Tumour hypoxia affects the responsiveness of cancer cells to chemotherapy and promotes cancer progression," Anticancer Agents Med. Chem. 2008, vol. 8, pp. 790-7.

[8] P. Vaupel and A. Mayer, "Hypoxia in cancer: significance and impact on clinical outcome," Cancer Metastasis Rev 2007, vol. 26, pp. 225-39.

[9] Y. Rong, D. L. Durden, E. G. Van Meir, and D. J. Brat, "Pseudopalisading necrosis in glioblastoma: a familiar morphologic feature that links vascular pathology, hypoxia, and angiogenesis," J. Neuropathol. 2006, vol. 6, pp. 529-539.

[10] D. Ribatti, B. Nico, E. Crivellato, and A. Vacca, "The structure of the vascular network of tumors," Cancer Lett. 2007, vol. 248 , pp. 18-23.

[11] P. Buchler, H. A. Reber, R. S. Lavey, J. Tomlinson, M. W. Buchler, H. Friess, and O. J. Hines, "Tumor hypoxia correlates with metastatic tumor growth of pancreatic cancer in orthotopic murine model," J. Surg. Res. 2004, vol. 120 , pp. 295-303.

[12] X. F. Li and J. A. O’Donoghue, "Hypoxia in microcospic tumors," Cancer Lett. 2008, vol. 264, pp. 172-180.

[13] A. V. Guitart, M. Hammoud, P. Dello Sbarba, Z. Ivanovic, and V. Praliron, "Slow-cycling/quiescence balance of hematopoietic stem cells is related to physiological gradient of oxygen," Exp. Hematol. 2010, vol. 38, pp. 847-51.

[14] K. Parmar, P. Mauch, J. A. Vergilio, R. Sackstein, and J. D. Down, "Distribution of hematopoietic stem cells in the bone marrow according to regional hypoxia," Proc. Natl. Acad. Sci. USA 2007, vol. 104, pp. 5431-5436

[15] A. Messerschmidt and R. Huber, "The blue oxidases, ascorbate oxidase, laccase and ceruplasmin," Eur. J.
Biochem. 1990, vol. 187, pp. 341-352.

[16] S. A. Roberts, A. Weichsel, G. Grass, K. Thakali, J. T. Hazzard, G. Tollin, C. Rensing, and W. R. Montfort, "Crystal structure and electron transfer kinetics of CueO, a multicopper oxidase required for copper homeostasis in Escherichia coli," Proc. Natl. Acad. Sci. USA 2002, vol. 99, pp. 2766-2771.

[17] G. R. Lee, G. E. Cartwright, and M. M. Wintrobe, "Heme biosynthesis in copper deficient swine," Proc. Soc. Exp. Biol. Med. 1968; vol. 127, pp. 977-81.

[18] G. R. Lee, Nacht S., J. N. Lukens, and G. E. Cartwright, "Iron metabolism in copper-deficient swine," J. Clin. Invest. 1968, vol. 47, pp. 2058-69.

[19] H. A. Ragan, S. Nacht, G. R. Lee, C. R. Bishop, and G. E. Cartwright "Effect of ceruloplasmin on plasma iron in copper-deficient swine" Am. J. Physiol. 1969, vol. 217, pp. 1320-3.

[20] S. Osaki, D. A. Johnson, and E. Frieden, "The possible significance of the ferrous oxidase activity of ceruloplasmin in normal human serum," J Biol Chem 1966, vol. 241, pp. 2746-51.

[21] P. Vachette, E. Dainese, V. B. Vasyliev, P. Di Muro, M. Beltramini, D. I. Svergun, V. De Filippis, and B. Salvato, "A key structural role for active site type 3 copper ions in human ceruloplasmin," J Biol Chem 2002; vol. 277, pp. 40823-31.

[22] B. N. Patel and S. David, "A novel GPI anchored form of ceruloplasmin expressed by astrocytes," J. Biol. Chem. 1997, vol. 272, pp. 20185-20190.

[23] R. R. Fortna, H. A. Watson, and S. E. Nyquist, "Glycosylphosphatidylinositol-anchored ceruloplasmin is expressed by rat Sertoli cells and is concentrated in detergent-insoluble membrane fractions," Biol. Reprod. 1999, vol. 61, pp. 1042-1049.

[24] J. H. Lee, C. E. Horak, C. Khanna, Z. Meng, L. R. Yu, T. D. Veenstra, and P. S. Steeg, "Alterations in Gemin5 expression contribute to alternative mRNA splicing patterns and tumor cell motility," Cancer Res. 2008, vol. 68, pp. 639-644.

[25] E. J. Mostad and J. R. Prohaska, "Glycosylphosphatidylinositol-linked ceruloplasmin is expressed in multiple rodent organs and is lower following dietary copper deficiency," Exp. Biol. Med. 2011, vol. 236, pp. 298-308.

[26] L. Marques, A. Auriac, A. Willemetz, J. Banha, B. Silva, F. Canonne-Hergaux, and L. Costa, "Immune cells and hepatocytes express glycosylphosphatidylinositolanchored ceruloplasmin at their cell surface," Blood Cells Mol Dis. 2012, vol. 48, pp. 110-120.

[27] Y. Ke and Z. Ming Qian, "Iron misregulation in the brain: a primary cause of neurodegenerative disorders" Lancet Neurol. 2003, vol. 2, pp. 246-53.

[28] L. Zecca, M. B. Youdim, P. Riederer, J. R. Connor, and R. R. Crichton, "Iron, brain ageing and neurodegenerative disorders" Nat. Rev. Neurosci. 2004, vol. 5, pp. 863-73.

[29] T. Ganz, "Cellular iron: ferroportin is the only way out," Cell Metabolism 2005, vol. 1, pp. 155-157.

[30] L. W. J. Klomp and J. D. Gitlin, "Expression of the 
ceruloplasmin gene in the human retina and brain: implications for a pathogenic model in aceruloplasminemia," Human Molecular Genetics 1996, vol. 5, pp. 1989-1996.

[31] H. Hochstrasser, J. Tomiuk, U. Walter, S. Behnke, J. Spiegel, R. Kruger, G. Becker, O. Riess, and D. Berg, "Functional relevance of ceruloplasmin mutations in Parkinson's disease," FASEB Journal 2005, vol. 19, pp. 1851-1853.

[32] K. Nakamura and N. Go, "Function and molecular evolution of multicopper blue proteins," Cell Mol. Life Sci. 2005, vol. 62, pp. 2050-2066.

[33] J. T. Hoopes and J. F. Dean, "Ferroxidase activity in a laccase-like multicopper oxidase from Liriodendron tulipifera," Plant Physiol. Biochem. 2004, vol. 42, pp. 27 33.

[34] P. Bielli and L. Calabrese, "Structure to function relationships in ceruloplasmin: a "moonlighting" protein," Cell Mol. Life Sci. 2002, vol. 59, pp. 1413-1427.

[35] G. Floris, R. Medda, A. Padiglia, and G. Musci, "The physiopathological significance of ceruloplasmin. A possible therapeutic approach," Biochem. Pharmacol. 2000 , vol. 60 , pp. $1735-1741$.

[36] R. D. Braun and A. L. Beatty, "Modeling of oxygen transport across tumor multicellular layers," Microvasc. Res. 2006, vol. 73, pp. 113-123.

[37] J. Healy and K. Tipton, "Ceruloplasmin and what it might do,” J. Neural Trasnm. 2007, vol. 114, pp. 777-781.

[38] E. D. Harris, "Ceruloplasmin and iron: vindication after 30 years," Nutrition 1999, vol. 15, pp. 72-73.

[39] V. Seshadri, P. L. Fox, and C. K. Mukhopadhyay, "Dual role of insulin in transcriptional regulation of the acute phase reactant ceruloplasmin," J. Biol. Chem. 2002, vol. 277, pp. 27903-11.

[40] C. K. Mukhopadhyay, B. Mazumder, and P. L. Fox, "Role of hypoxia-inducible factor- 1 in transcriptional activation of ceruloplasmin by iron deficiency," J. Biol. Chem. 2000, vol. 275 , pp. $21048-54$
[41] F. Martin, T. Linden, D. M. Katschinski, F. Oehme, I. Flamme, C. K. Mukhopadhyay, K. Eckhardt, J. Troger, S. Barth, G. Camenisch, and R. H. Wenger, "Copperdependent activation of hypoxia-inducible factor (HIF)-1: implications for ceruloplasmin regulation," Blood 2005, vol. 105, pp. 4613-9.

[42] J. Sarkar, V. Seshadri, N. A. Tripoulas, M. E. Ketterer, P. L. Fox, "Role of ceruloplasmin in macrophage iron efflux during hypoxia," J. Biol. Chem. 2003, vol. 278, pp. 44018-24.

[43] O. Erel, "Automated measurement of serum ferroxidase activity," Clin. Chem. 1998, vol. 44, pp. 2313-9.

[44] M. I. Surks, K. S. Chinn, and L. R. Matoush, "Alterations in body composition in man after acute exposure to high altitude," J. Appl. Physiol. 1966, vol. 21, pp. 1741-6.

[45] R. E. Fleming, I. P. Whitman, and J. D. Gitlin, "Induction of ceruloplasmin gene expression in rat lung during inflammation and hyperoxia," Am. J. Physiol. 1991, vol. 260, pp. 68-74.

[46] S. Guller, C. S. Buhimschi, Y. Y. Ma, S. T. Huang, L. Yang, E. Kuczynski, E. Zambrano, C. J. Lockwood, and I. A. Buhimschi, "Placental expression of ceruloplasmin in pregnancies complicated by severe preeclampsia," Lab. Invest. 2008, vol. 88, pp. 1057-67.

[47] J. Bourhis, "Hypoxia response pathways and radiotherapy for head and neck cancer," J. Clin. Oncol. 2006, vol. 24, pp. $725-726$.

[48] S. D. Young, R. S. Marshall, and R. P. Hill, "Hypoxia induces DNA over replication and enhances metastatic potential of murine tumor cells," Proc. Natl. Acad. Sci. USA 1988, vol. 85, pp. 9533-9537.

[49] Y. Guan, K. R. Reddy, Q. Zhu, Y. Li, P. Weerasinghe, J. Prchal, G. L. Semenza, and N. Jing, "G-rich oligonucleotides inhibit HIF-1 alpha and HIF-2 alpha and block tumor growth," Mol. Ther. 2010, vol. 18, pp. 188 97.

[50] Y. Huang, J. Yu, C. Yan, J. Hou, G. Zhang, Z. Fu, and X. Wang, "Effect of small interfering RNA targeting hypoxia-inducible factor-1 alpha on radiosensitivity of PC3 cell line," Urology 2012, vol. 79, pp. 744.e17-24. 